\title{
Binocular summation in the evoked cortical potential $^{1}$
}

\author{
NEIL R. BARTLETT, UNIVERSITY OF ARIZONA
}

ROBERT G. EASON ANO CARROLL T. WHITE, U. S. NAVY ELECTRONICS LABORATORY, SAN DIEGO

Computer-averaged evoked potentials were recorded from six subjects presented with flashes under conditions of binocular and monocular viewing, with a device fitted over each eye to produce ganzfeld conditions. Tests were run with red light and with blue. Analysis of the evoked potentials indicates a substantially larger amplitude with binocular stimulation.

DeSilva and Bartley (1930) have demonstrated there is an appreciable change in binocular brightness when the illumination to one eye is altered; brightness is judged higher if both eyes are equally illuminated than if the illumination to one eye is reduced. Matin (1962) has shown binocular summation for threshold for signals peripheral to the line of regard and falling on corresponding retinal regions, and further established that the increased probability for detection with binocular viewing is greater than would be predicted from the assumption that each eye operates independently of the other. Together these two reports constitute convincing behavioral evidence that for processing information on the intensity of illumination there is a common sensory path for the two eyes central to the optic chiasma. A physiological analogue of these human behavioral analyses is in a study of the electric potentials in the visual cortex of anesthetized cats. Auerbach et al (1961) found that such cortical potentials in response to binocular stimulation were larger than those to monocular.

This report is closely related to the last-named. It concerns an investigation of the computed average evoked response as recorded from the scalp of human, alert Ss, under conditions of monocular and binocular ganzfeld stimulation. The details of the experimental arrangements have been described elsewhere (Eason et al, 1964). Briefly, a Mnemotron computer of average transients was fed directly by an Offner type $R$ dynograph equipped with a $9806 \mathrm{~A}$ input complex. Occipital cortical potentials were picked up with monopolar electrodes. The computed average potentials from a set of stimulus presentations were recorded on graph paper with a Moseley $X-Y$ plotter, model 202. Significant details peculiar to this study are the following.

The $S$ was fitted with two scalp electrodes rather than one; the active electrodes, connected to a single input, were $2.5 \mathrm{~cm}$ above the inion, the flrst $2.5 \mathrm{~cm}$ to the left and the other $2.5 \mathrm{~cm}$ to the right of the midline. The neutral electrodes were attached to the ear lobes, and were also tied electrically. Further,
$S$ wore a ganzfeld device (half a table-tennis ball) taped securely over each eye. During all observations a dimly illuminated surface, immediately below the stimulus window, was exposed continuously so as to maintain a state of low light adaptation. The stimulus was the flash from a Grass photostimulator, model PS-2, set at level $I-16$ for the red condition and at I-8 for the blue condition. The stimulator was mounted flush outside a window of the electrically-shielded room in which $S$ sat. The flashes were presented at the rate of $.5 / \mathrm{sec}$.

Three averaged potential records, each based on 120 evoked responses, were obtained for each of six Ss under six different viewing conditions generated by stimulating the right, left, or both eyes with either red (Wratten fulter 29) or blue (filter 49B) light. Each $S$ participated in a total of six sessions, three for each color. The order in which the stimulus flash was presented under the three ocular conditions was balanced over time both within and across sessions. Within a session, flashes were presented in blocks of 40 for each method of observation, there being three blocks for each method. Between block pre-

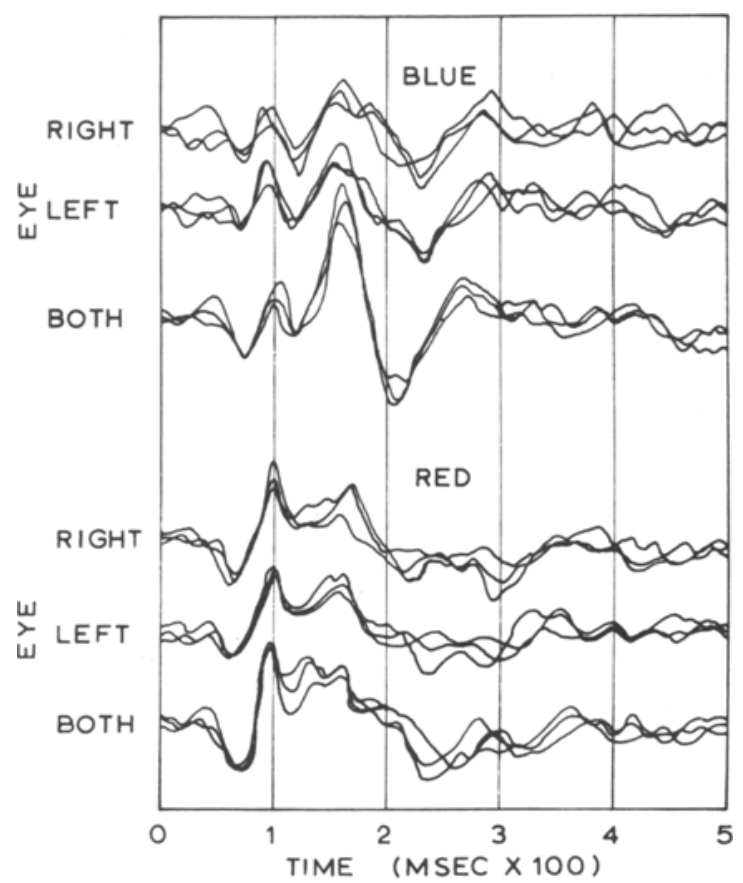

Fig. 1. Evoked potential records obtained from subject $E$. Each record represents the summation of 120 responses. Negative downward. 
Table 1. Mean variance, 50 to $300 \mathrm{msec}$, of evoked cortical potential. Numbers in parentheses are for the blue condition; the others for red.

\begin{tabular}{cccc} 
Subject & Right & $\begin{array}{c}\text { Eye Used } \\
\text { Left }\end{array}$ & Both \\
\hline W & 1095 & 1266 & 1698 \\
& $(364)$ & $(292)$ & $(471)$ \\
E & 429 & 418 & 925 \\
& $(447)$ & $(469)$ & $(1210)$ \\
F & 525 & 394 & 788 \\
& $(157)$ & $(187)$ & $(206)$ \\
B & 200 & 321 & 553 \\
& $(165)$ & $(229)$ & $(391)$ \\
P & 1503 & 994 & 1364 \\
& $(2075)$ & $(1643)$ & $(2992)$ \\
L & 779 & 876 & 1388 \\
& $(452)$ & $(204)$ & $(686)$ \\
\hline
\end{tabular}

As a check on the statistical confidence level for accepting the differences shown in Table 1 as evidence for binocular summation, an analysis of variance was conducted on the 36 indices. The resulting $F$ tests proved the summation hypothesis tenable with a confidence exceeding 99.9\%. Further, as one would surmise from Table 1 , the statistical tests show Ss differ significantly one from another in the variance indices, and the effect of changing color varies significantly from subject to subject.

sentations, S changed viewing conditions by occluding the appropriate eye with his hand, or by moving his hand to permit binocular exposure.

The complete records for one $S$ are presented in Fig. 1. The evoked cortical activity occurring during the half-second following stimulation is shown.

The records were analyzed by reading, at each successive $12.5 \mathrm{msec}$ interval, the height of the wave above the bottom of the lowest trough; readings were made from $50 \mathrm{msec}$ following the flash to 300 msec. Then the variance about their means was calculated for these 21 readings. Thus the resulting index for the wave form is related to power. Table 1 exhibits the means of the three variances for each viewing condition and for each color for the six Ss. For five the binocular condition shows substantially larger means, and the sixth, (P), the binocular shows a larger index when blue light is used, but not when red light is employed.

As a check on the statistical confidence level for accepting the differences shown in Table 1 as evidence for binocular summation, an analysis of variance was conducted on the 36 indices. The resulting $F$ tests proved the summation hypothesis tenable with a confidence exceeding $99.9 \%$. Further, as one would surmise from Table 1, the statistical tests show Ss differ significantly one from another in the vartance indices, and the effect of changing color varies significantly from subject to subject.

\section{References}

Auerbach, E., Beller, A. J., Henkes, H. E., \& Goldhaber, G. Electric potentials of retina and cortex of cats evoked by monocular and binocular photic stimulation. Vis, Res., 1961, 1, 166-182.

Desilva, H. R., \& Bartley, S. H. Summation and subtraction of brightness in binocular perception. Brit. J. Psychol., 1930, $20,241-250$.

Eason, R. G., Aiken, L. R., White, C. T., \& Lichtenstein, M. Activation and behavior: II. Visually evoked cortical potentials in man as indicants of activation level. Percept. mot. Skills, 1964, 19, 875-895.

Matin, L. Binocular summation at the absolute threshold of peripheral vision. J. Opt. Soc. Amer., 1962, 52, 1276-1286.

\section{Note}

1. We thank. J. A. Hoke for technical assistance. Study supported in part by NSF (grants GS-231 and GB-4067) and in part by the Navy Electronics Laboratory.

(Accepted for publication October 3, 1967.) 